\title{
Pneumothorax Post Brachial Plexus Block Guided by Ultrasound: a Case Report
}

\author{
Beatriz L. S. Mandim ${ }^{1}$, Rodrigo R. Alves ${ }^{2}$, Rodrigo Almeida ${ }^{3}$, João Paulo J. Pontes ${ }^{4}$, Lorena J. Arantes ${ }^{4}$, \\ Fabíola P. Morais ${ }^{5}$
}

Summary: Mandim BLS, Alves RR, Almeida R, Pontes JPJ, Arantes LJ, Morais FP - Pneumothorax Post Brachial Plexus Block Guided by Ultrasound: a Case Report.

Background and objectives: Brachial plexus block is used for upper limbs anesthesia. The use of ultrasound-guided (USG) technique for blockade has become popular in recent years, facilitating its execution by providing real-time images of the plexus and surrounding structures while minimizing complications. The purpose of this report is to describe a case of pneumothorax following ultrasound-guided interscalene block.

Case Report: Male patient, 49 years old, weight $62 \mathrm{~kg}$ and height $1.72 \mathrm{~m}$, slender, smoker, asymptomatic, ASA II E. The patient underwent surgical repair of right ulna open fracture through USG-guided interscalene brachial plexus block with axillary supplementation. After sedation and antisepsis, the linear probe of the USG apparatus was placed perpendicular to the interscalene groove (12 Hz), and stimucath A50 introduced in plane. After visualization of nerve trunks, $20 \mathrm{~mL}$ of ropivacaine $0.5 \%$ was administered with axillary block suplementation (same volume and concentration of anesthetic). At the end of surgery, the patient complained of respiratory-dependent chest pain associated with dyspnea and decreased pulse oximetry ( $91 \%$ in room air), but hemodynamic stable (BP $=130 / 70$ and HR $=84 \mathrm{bpm})$. Although pulmonary auscultation was normal, chest X-ray showed the presence of right pneumothorax. Water seal chest drainage was performed, after which the patient reported improvement of symptoms and was discharged from hospital in good general condition after 8 days.

Conclusion: Despite the dynamic visualization of cervical structures with USG, interscalene block may result in pneumothorax. An unusual higher pleural dome due to the hyperinflated lung (smoking) probably facilitated the accidental pleural puncture.

Keywords: Anesthesia, Conduction; Brachial Plexus; Ultrasonography; Pneumothorax.

(C2012 Elsevier Editora Ltda. All rights reserved.

\section{INTRODUCTION}

Interscalene brachial plexus block, originally described by Winnie in the early 70s, provides surgical anesthesia and postoperative analgesia for procedures performed on the shoulder and proximal upper limbs ${ }^{1}$. In the last three decades, the elicitation of paresthesia and/or the production of motor response after nerve stimulation have been used as methods capable of indicating needle-nerve proximity during peripheral nerve block. Because they are performed without direct visualization of adjacent structures, these two traditional techniques are associated with serious complications due to the close proximity of plexus to important structures at this site,

Received from Faculdade de Medicina da Universidade Federal de Uberlândia, Minas Gerais, Brazil.

1. Co-responsible for CET/SBA, Faculdade de Medicina da Universidade Federal de Uberlândia (UFU)

2. Instructor at CET/SBA, Faculdade de Medicina, UFU

3. Anesthesiologist, Hospital de Clínicas, UFU

4. Anesthesiology Graduate at CET/SBA, Faculdade de Medicina, UFU

5. Undergraduate Student, Faculdade de Medicina, UFU

Submitted on September 19, 2011.

Approved on March 20, 2012.

Correspondence to:

Beatriz L S Mandim, MD

Berenice Rezende Diniz 300 casa 22

38411162 - Uberlandia, MG, Brazil

E-mail:mandim@uol.com.br and may cause inadvertent intravascular injection, respiratory complications, unintentional spinal anesthesia, and brachial plexus injuries ${ }^{2}$. The use of ultrasound guidance (USG) facilitates brachial plexus block providing images of the plexus and surrounding structures, allowing real-time direction of the needle toward the target nerve, which provides the precise deposition of anesthetic solution under constant observation, in addition to minimizing complications ${ }^{3}$. Although described as a complication of traditional techniques ${ }^{4}$, pneumothorax also appears as an acute complication of the interscalene block guided by ultrasound ${ }^{5}$. The aim of this study was to describe this complication after the use of USG for interscalene brachial plexus block.

\section{CASE REPORT}

Male patient, 49 years old, weight $62 \mathrm{~kg}$ and height $1.72 \mathrm{~m}$, presenting long-time smoking (1 pack per day for 30 years) as the only comorbidity, with no respiratory symptoms or use of medications (physical status ASA II E). He was taken to the operating room for surgical repair of right ulna open fracture (plate and screws fixation). Before surgery, the patient showed hemoglobin $=12.5 \mathrm{~g} \cdot \mathrm{L}^{-1}$ and hematocrit $=37.4 \%$. On clinical examination, an increased pubis-vertex distance was observed in the patient with a slender biotype.

Patient was informed of the anesthetic technique, latency, duration of the procedure, and possible complications. We 
opted for USG interscalene brachial plexus block (USG Press Sonoline Siemens, Siemens Medical Systems, Issaquah, WA, USA) with block supplementation via axillary approach.

After mild sedation with $2 \mathrm{mg}$ of midazolam (Dormium ${ }^{\circledR}$ - Union Chemical) and $100 \mathrm{mcg}$ of fentanyl (Fentanest ${ }^{\circledR}$ Cristália), an oxygen-humid nasal catheter was placed (2 L. $\left.\mathrm{min}^{-1}\right)$ and the patient positioned in supine, with the right arm alongside the trunk, slight rotation of the head to the contralateral side of the blockade to facilitate the anatomical landmarks perception. After antisepsis with $70 \%$ alcohol, anesthetic button was performed with $2 \mathrm{~mL}$ of lidocaine $2 \%$ without vasoconstrictor. Gel was applied at the posterior cervical tri-

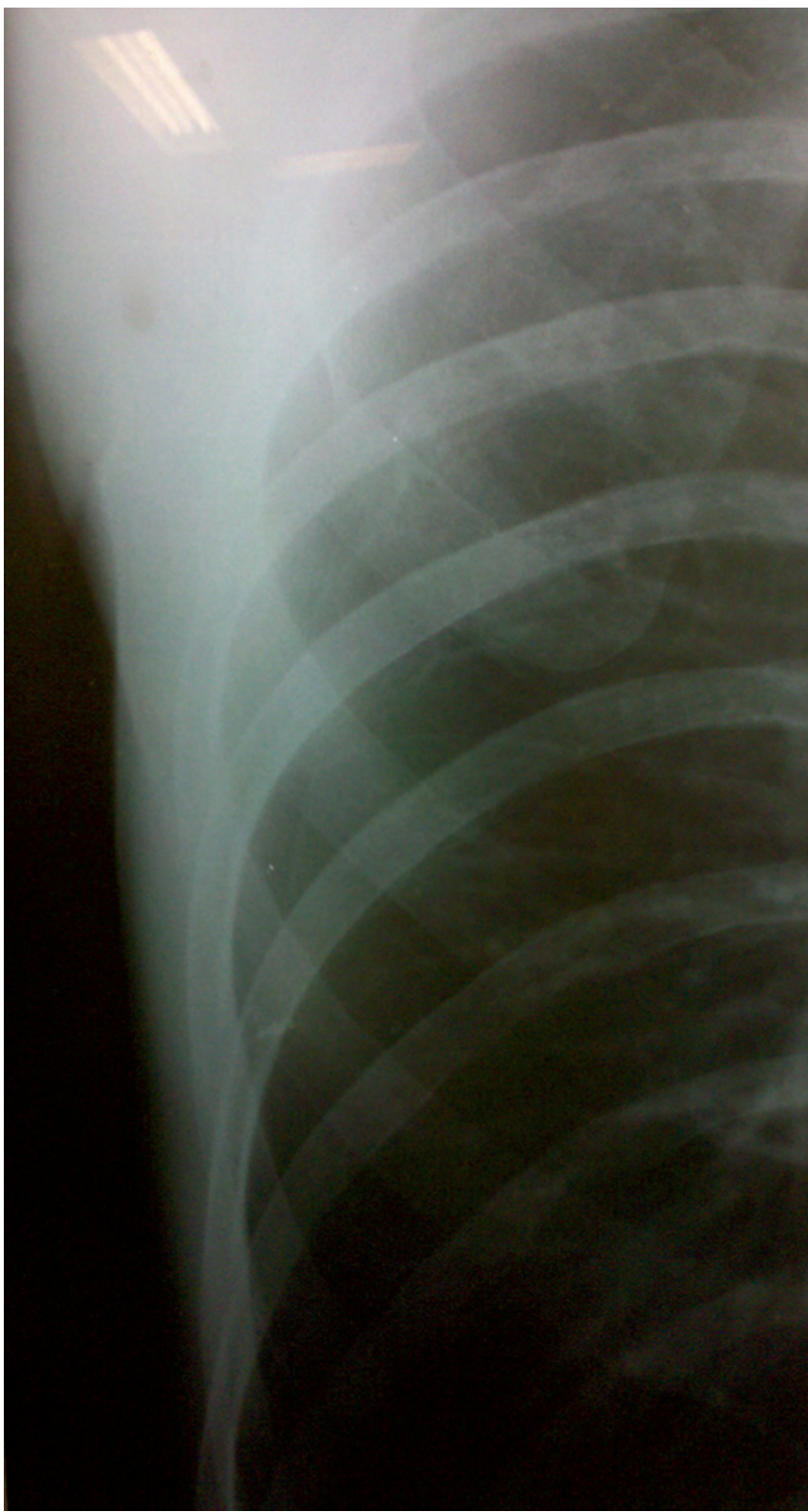

Figure 1 - Chest X-ray with Red Arrows Showing Pneumothorax Line. angle, and the linear probe of USG apparatus was placed with the long axis perpendicular to the interscalene groove, frequency adjusted to $12 \mathrm{~Hz}$, and stimucath A50 (50 mm) introduced, in plane, in relation to probe in the interscalene groove. After nerve trunks visualization, the needle was deepened until piercing the fascia interscalene, and $20 \mathrm{~mL}$ of ropivacaine $0.5 \%$ (Ropi - Cristália $\AA$ ) was applied, observing anesthetic solution dispersion. This block was completed by the axillary approach, also guided by ultrasound, with $20 \mathrm{~mL}$ of the same solution (ropivacaine $0.5 \%$ ). After 25 minutes latency, sensory and motor block were obtained in the entire right forearm. The procedure lasted 100 minutes, during which $1,500 \mathrm{~mL}$ of crystalloids were infused $(1,000 \mathrm{~mL}$ Ringer's lactate and $500 \mathrm{~mL}$ Ringer's solution).

The patient had no complaints and remained stable, from the cardiovascular standpoint, with $\triangle$ SBP $(90-120 \mathrm{~mm} \mathrm{Hg}$ ), $\triangle \mathrm{DBP}(50-60 \mathrm{~mm} \mathrm{Hg})$, and $\Delta \mathrm{HR}(60-80 \mathrm{bpm})$ throughout the procedure. From the respiratory standpoint, the patient was breathing spontaneously, and pulse oximetry ranged from 96$97 \%$ with nasal oxygen catheter (2 L. $\left.\mathrm{min}^{-1}\right)$. After the procedure, with the removal of nasal oxygen catheter, the patient developed respiratory-dependent chest pain associated with dyspnea and decreased pulse oximetry (up to $91 \%$ on room air), remaining, however, hemodynamic stable $(B P=130 / 70$ and $\mathrm{HR}=84 \mathrm{bpm}$ ). Patient's auscultation was performed showing no difference between the two lung fields or reduction of vesicular breath sounds on the right. Chest X-ray was performed (Figure 1) with patient in the seating position, which showed the presence of pneumothorax in right hemithorax.

The case was discussed with the general surgery team that recommended closed chest drainage (tube number 34) on water seal for 48 hours, which was performed in the operating room, with the consent of the patient, without complications. The patient evolved with improved dyspnea, chest drainage functioning properly in oscillation. During hospitalization, tube repositioning and continuous suction were required. The tube was removed eight days after the procedure and patient discharged in good general condition with follow-up at the thoracic surgery outpatient clinic service.

\section{DISCUSSION}

With direct sonographic visualization of nerve structures, several potential advantages over the so-called "blind" nerve identification technique have been reported with reduced risk of pleural puncture as one of them ${ }^{5}$. In our patient, despite the use of the equipment and trained operator, this rare complication occurred. A recent study found one case of pneumothorax in 144 patients $(0.7 \%$ incidence) after blockade and placement of interscalene catheter for controlling postoperative pain in ultrasound-guided shoulder surgery ${ }^{6}$, confirming the low incidence of this complication. Many studies claim that the brachial plexus block guided by ultrasound has higher success rate than those guided by the peripheral nerve stimulator. However, the studies were not comprehensive enough to conclude that the use of ultrasound reduces the risk of nerve 
injury, local anesthetic toxicity, or pneumothorax ${ }^{7}$. It is known that interscalene brachial plexus block may lead to secondary changes in respiratory function. Respiratory failure may occur due to pneumothorax or inadvertent injection of anesthetic solution into the subarachnoid or epidural space ${ }^{8}$. However, the most common respiratory impairment occurs secondary to ipsilateral hemidiaphragmatic paresis ${ }^{9}$, with up to $100 \%$ incidence ${ }^{10}$ when $20 \mathrm{~mL}$ or more of local anesthetic solution is injected reducing the pulmonary function tests by $20-40 \%$ within 15 minutes of blockade and lasting for at least 9 hours ${ }^{11}$.

Despite the patient's smoking history and probably some degree of chronic obstructive pulmonary disease due to the radiographic finding of pulmonary hyperinflation (Figure 2 ), he was clinically asymptomatic (no dyspnea on effort), and therefore right hemidiaphragmatic paresis alone would be unable to explain the patient's respiratory impairment with significant drop in saturation and clinical complaints. Moreover, the hypothesis of inadvertent subarachnoid or epidural anesthesia can be ruled out, because when this occurs lung function impairment is acute in the first minutes after blockade with diffuse bilateral symptoms, resembling acute quadriplegia ${ }^{8}$, which is not similar to our patient's condition that began after the surgical procedure.

As seen in this report, pneumothorax secondary to brachial plexus block may appear hours after the blockade and surgery, clinically manifesting as dyspnea and chest pain that is intensified mainly on inspiration ${ }^{8}$. It may resolve spontaneously without treatment, as it is subclinical in most cases 7. However, according to some authors ${ }^{12}$, chest tube drainage is always the initial treatment of choice in secondary pneumothorax, except in stable patients with very small pneumothorax (laminar, or $<1 \mathrm{~cm}$ ). The rationale for this procedure lies in the fact that patients with pulmonary disease have lower lung compliance, and often what appears to be a small pneumothorax is enough to bring serious consequences ${ }^{12}$. According to the literature, the general surgery team opted for water-seal drainage due to the patient's symptoms and probable subclinical impairment of lung function by smoking.

In hemidiaphragmatic paresis after phrenic nerve block and pneumothorax, ipsilateral lung auscultation shows reduced vesicular breath sounds, a fact not seen in this case,

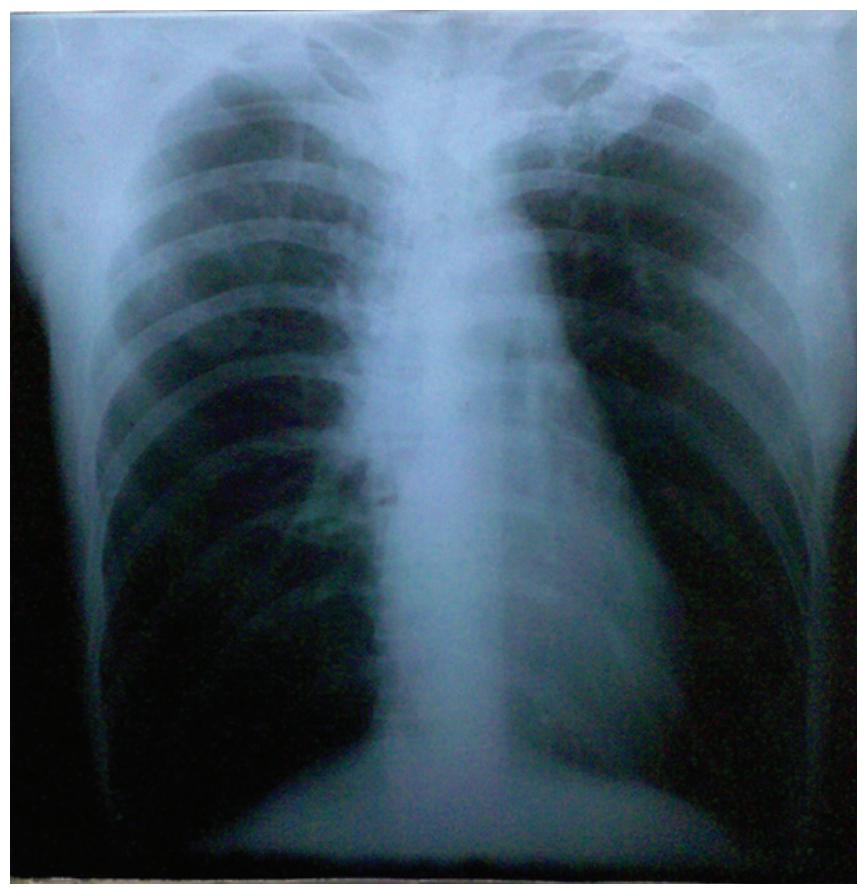

Figure 2 - Chest X-ray (posteroanterior) of Patient with signs of Pulmonary Hyperinflation.

requiring confirmation by chest $\mathrm{X}$-ray, which in case of doubt, according to literature ${ }^{8}$, should always be requested to exclude pneumothorax.

Pneumothorax, although more associated with supraclavicular brachial plexus block ${ }^{13,14}$, may occur with interscalene approach even in trained hands and real-time image through the aid of a USG device, as in the above-mentioned case. A pleural dome higher than usual due to a hyperinflated lung (sequelae of long-time smoking), probably facilitated inadvertent pleural puncture, as observed in other reports ${ }^{15,16}$. Even with the increased use of USG as an aiding tool for performing brachial plexus block in the cervical region, caution and deep knowledge of this region anatomy remain essential, as it is related to important anatomical structures, and blocks are not free from complications. 
MANDIM, ALVES, ALMEIDA E COL.

\section{REFERENCES}

1. Winnie AP - Interscalene brachial plexus block. Anesth Analg, 1970;49(3):455-466. 
2. Perlas A, Chan VWS - Ultrasound-guided interscalene brachial plexus block. Tech Reg Anesth Pain Manag, 2004;8:143-148.

3. Marhofer P, Chan VWS - Ultrasound-guided regional anesthesia: current concepts and future trends. Anesth Analg, 2007;104:1265-1269.

4. Borgeat $A$, Ekatodramis $G$, Kalberer $F$ et al. - Acute and nonacute complications associated with interscalene block and shoulder surgery. Anesthesiology, 2001;95(4):875-880.

5. Helayel PE, Conceição DB, Oliveira Filho GR - Bloqueios nervosos guiados por ultrassom. Rev Bras Anestesiol, 2007;57(1):106-123.

6. Bryan NA, Swenson JD, Greis PE, Burks RT - Indwelling interscalene catheter use in an outpatient setting for shoulder surgery: technique, efficacy, and complications. J Shoulder Elbow Surg, 2007;16:388395.

7. Klaastad O, Sauter AR, Dodgson MS - Brachial plexus block with or without ultrasound guidance. Curr Opin Anaesthesiol, 2009;22(5):655660.

8. Urmey WF - Pulmonary Complications of Interscalene Brachial Plexus Blocks. [Citado em agosto 2011]. Disponível em http://www. nysora.com/files/uploaded/meetings-conferences/09symposium/ lecturenotes/1115am-UrmeyWFUpulcomp.pdf

9. Gentili M, Lefoulon-Gourves M, Mamelle J et al. - Acute respiratory failure following interscalene block: complications of combined general and regional anesthesia. Reg Anesth, 1994;19:292-293.

10. Urmey W, Gloeggler P - Pulmonary function changes during interscalene block: effects of decreasing local anesthetic injection volume. Reg Anesth, 1993;18:244-249.

11. Urmey W, Gloeggler P - Effects of bupivacaine $0.5 \%$ compared with mepivacaine $1.5 \%$ used for interscalene brachial plexus block (abstract). Reg Anesth, 1992; 17:13.

12. Andrade Filho LO, Campos JRM, Haddad R - Pneumotórax. J Bras Pneumol, 2006;32(4):212-216.

13. Winnie AP - Plexus anesthesia, perivascular techniques of brachial plexus block. Philadelphia, WB Saunders, 1990, pp. 176-181.

14. Neal J, Hebl J, Gerancher $\mathrm{J}$ et al. - Brachial plexus anesthesia: essentials of our current understanding. Reg Anesth Pain Med, 2002:27:401-428.

15. Schroeder KM, Blake JM, Angelini G et al. - Pneumothorax after ultrasound guided interscalene block for shoulder surgery: a report of two cases. Reg Anesth Pain Med, 2009;32:105.

16. Bhatia A, Lai J, Chan VW et al. - Case report: pneumothorax as a complication of the ultrasound-guided supraclavicular approach for brachial plexus block. Anesth Analg, 2010;111(3):817-819. 